\title{
Chapter 5 \\ Is the Real Number Line Something to Be Built, or Occupied?
}

\author{
Hyman Bass
}

\begin{abstract}
Klein emphasized geometry and intuition, and made the concept of function central to mathematics education. In fact, number and operations form the backbone of the school mathematics curriculum. A high school graduate should comfortably and capably meet an expression like, "Let $y=f(x)$ be a function of a real variable $x$," implying that the student has a robust sense of the real number continuum, the home of $\mathrm{x}$. This understanding is a central objective of the school mathematics curriculum, taken as a whole. Yet there are reasons to doubt whether typical (U.S.) high school graduates fully achieve this understanding. Why? And what can be done about this? I argue that there are obstacles already at the very foundations of number in the first grades. The construction narrative of the number line, characteristic of the prevailing curriculum, starts with cardinal counting and whole numbers and then builds the real number line through successive enlargements of the number systems studied. An alternative, based on ideas advanced by V. Davydov, the occupation narrative, begins with pre-numerical ideas of quantity and measurement, from which the geometric (number) line, as the environment of linear measure, can be made present from the beginning, and wherein new numbers progressively take up residence. I will compare these two approaches, including their cognitive premises, and suggest some advantages of the occupation narrative.
\end{abstract}

Keywords Quantity $\cdot$ Unit $\cdot$ Measurement $\cdot$ Number $\cdot$ Counting Real number line $\cdot$ Early childhood mathematics

This paper is adapted from a presentation at the workshop, Math Matters in Education (Texas A \& M University, March, 2015) in honor of Roger Howe.

\footnotetext{
H. Bass $(\bowtie)$

University of Michigan, Ann Arbor, USA

e-mail: hybass@umich.edu

(C) The Author(s) 2019

H.-G. Weigand et al. (eds.), The Legacy of Felix Klein, ICME-13 Monographs, https://doi.org/10.1007/978-3-319-99386-7_5
} 


\subsection{Introduction}

Klein's mathematical work emphasized geometry and intuition.

As regards my own higher lectures, I have pursued a certain plan in selecting the subjects for different years, my general aim being to gain, in the course of time, a complete view of the whole field of modern mathematics, with particular regard to the intuitional or (in the highest sense of the term) geometrical standpoint.

-Klein (2000, p. 96)

His work in school mathematics education gave center stage to the concept of function (Klein 2000, p. 4).

We, who are called the reformers, would put the function concept at the very center of instruction, because, of all the concepts of the mathematics of the past two centuries, this one plays the leading role wherever mathematical thought is used. We would introduce it into instruction as early as possible with constant use of graphical method, the representation of functional relations in the $\mathrm{x} y$ system, which is used today as a matter of course in every practical application of mathematics.

The learners that Klein had in mind were presumed to have a well-founded understanding (both formal and intuitive) of the real number line, of the " $\mathrm{x}$ " in $\mathrm{f}(\mathrm{x})$, of Euclidean geometry in dimension one. This paper addresses the fact that this essential foundational understanding may be less secure with some current curricular treatments.

The device beyond praise that visualises magnitudes, and at the same time the natural numbers articulating them, is the number line, where initially only the natural numbers are individualised and named. In the didactics of secondary instruction the number line has been accepted, though it is often still imperfectly and inexpertly exploited.

-Freudenthal (1983, p. 101)

My purpose here is to contrast the development of the number line common to most current curricula with an alternative proposed by V. Davydov, one that, I would argue, is closer in spirit to Klein's sensibility.

... the students' creation of a detailed and thorough conception of a real number, underlying which is the concept of quantity, is currently the end purpose of this entire instructional subject, from grade 1 to $10 \ldots$ the teacher, relying on the knowledge previously acquired by the children, introduces number as a ... representation of a general relationship of quantities, where one of the quantities is taken as a measure and is computing the other.

—Davydov (1990, pp. 167, 169)

\subsection{The Construction Narrative of the Real Number Line}

For intuitively meaningful parts of mathematics, there is a significant difference between the logical and the psychological points of entry, the latter being typically located somewhere midlevel in the logical hierarchy. The logical foundations are no 
less intuitively abstract than are the more sophisticated structures that expand beyond our initial intuitions.

In the case of the real number line, $\mathbb{R}$, its twentieth century, set theory based, construction starts with the whole numbers, and continues (Peano Axioms) with successive enlargements, to integers, $\mathbb{Z}$, rational numbers, $\mathbb{Q}$, and finally reaching $\mathbb{R}$, by a process of geometric completion (filling invisible holes). This is what I call the construction narrative of the number line. In many school curricula the real number line is constructed by some rough approximation of this construction narrative: First, counting (whole) numbers; then, in some order, negative integers and positive fractions; merging into rational numbers; and finally real numbers, either constructed using some form of limits, or, commonly, just noting the existence of some irrational numbers, like $\sqrt{2}$, and vaguely leaving the real numbers underspecified as "the rationals plus the irrationals."

The starting point of the construction narrative seem natural enough since humans (and other species) are biologically endowed with some primordial sense of small cardinal counting:

It is now widely acknowledged that the typical human brain is endowed by evolution with a mechanism for representing and discriminating numbers ... when I talk about numbers I do not mean just our familiar symbols - counting words and 'Arabic' numerals, I include any representation of the number of items in a collection, more formally the cardinality of the

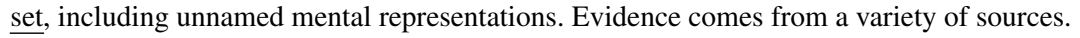

-Brian Butterworth (2015)

A more spiritual, but less scientific evocation of this is Kronecker's dictum, "God made the integers, all else is the work of man."

The construction narrative begins with whole numbers and counting and progressively introduces new number systems. In all but one case (from rational to real numbers), the new system is created to enable solutions to equations formulated, but not solvable, in the previous system. In each extension it is tacitly presumed, but not generally proved, that the arithmetic operations extend and that Basic Rules of Arithmetic (commutativity, associativity, distributivity, etc.) continue to hold. 


\begin{tabular}{|c|c|c|}
\hline \multicolumn{3}{|c|}{$\begin{array}{c}\text { The Construction Narrative of the Real Number Line } \\
\text { Cognitive Premise: Children's early discernment of small cardinals and large } \\
\text { differences }\end{array}$} \\
\hline Number Systems & Models & Conceptual frame \\
\hline Whole numbers & $\begin{array}{l}\text { (Finite) sets; disjoint union as sum; } \\
\text { the "Number Queue" }\end{array}$ & Cardinal/Ordinal \\
\hline 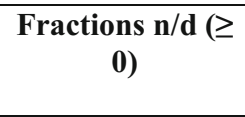 & $\begin{array}{l}\text { Part-whole images } \\
\text { Solve: } \mathrm{a} \cdot \mathrm{x}=\mathrm{b}\end{array}$ & $\begin{array}{l}\text { Use } 1 / \mathrm{d} \text { as unit. Need } \\
\text { common } \mathrm{d} \text { for } \\
\text { addition }\end{array}$ \\
\hline Integers* & $\begin{array}{l}\text { Negatives; subtraction } \\
\text { Solve: } \mathrm{a}+\mathrm{x}=\mathrm{b}\end{array}$ & $\begin{array}{l}\text { Reflection through } 0 \\
\text { Take away; compare. }\end{array}$ \\
\hline $\begin{array}{l}\text { Rational } \\
\text { numbers }\end{array}$ & $\begin{array}{c}\text { Formal synthesis of fractions } \geq 0 \text { and } \\
\text { negative numbers }\end{array}$ & $\begin{array}{l}\text { Mirror reflection of } \\
\quad \text { fractions } \geq 0\end{array}$ \\
\hline $\begin{array}{c}\text { Irrational } \\
\text { numbers }\end{array}$ & $\begin{array}{c}\text { Miscellaneous natural examples: } \sqrt{2}, \pi, \\
\text { e } \\
\text { Only } \sqrt{2} \text { is proved }\end{array}$ & $\begin{array}{l}\text { Incommensurability } \\
\text { with } 1\end{array}$ \\
\hline Real numbers & $\begin{array}{l}\text { "Everything else." Infinite decimals. } \\
\text { A significant conceptual gap }\end{array}$ & $\begin{array}{l}\text { All points on the } \\
\text { (continuous) number } \\
\text { line }\end{array}$ \\
\hline $\begin{array}{l}\text { Complex } \\
\text { numbers }\end{array}$ & $\begin{array}{l}\text { "The complex plane" } \\
\text { Solve: } \mathrm{x}^{2}+1=0\end{array}$ & \\
\hline
\end{tabular}

$\left({ }^{*}\right)$ The curricular order of "Integers" and "Fractions $(\geq 0)$ " is sometimes reversed.

\subsection{Difficulties with the Construction Narrative}

\subsubsection{The Whole Number/Fraction Divide}

Whole numbers are conceived as cardinals of (discrete) sets, while fractions are conceived as relative measures of two (continuous) quantities, and so they seem, at first sight, to be different a species of numbers. The whole number 7 is treated as a noun, whereas, when thinking of $3 / 4$, it is hard to resist adding the word "of." A fraction is conceptually an operator on quantities, not a conceptually free-standing mathematical object, since, unlike cardinal, the unit of measure is unspecified and not implicit. This difference makes it difficult to arrange for these two number populations and their interactions to harmoniously cohabit the same (real) number universe. Of course cardinal is appropriately viewed as a special (discrete) regime of measurement, but this perspective is not initially needed, and so not made explicit. 


\begin{tabular}{|l|l|}
\hline \multicolumn{1}{|c|}{ Whole numbers } & Fractions \\
\hline $\begin{array}{l}\text { A whole number is, conceptually, a } \\
\text { mathematical object. "7" }\end{array}$ & $\begin{array}{l}\text { A fraction is, conceptually, a } \\
\text { mathematical operator. "3/4 of . .." }\end{array}$ \\
\hline $\begin{array}{l}\text { A whole number is the (discrete) } \\
\text { measure (cardinal) of a set }\end{array}$ & $\begin{array}{l}\text { A fraction is the relative measure of two } \\
\text { quantities }\end{array}$ \\
\hline $\begin{array}{l}\text { Addition/subtraction corresponds to } \\
\text { composition/decomposition (set union) }\end{array}$ & $\begin{array}{l}\text { Addition/subtraction corresponds to } \\
\text { composition/decomposition of quantities }\end{array}$ \\
\hline $\begin{array}{l}\text { Multiplication corresponds to repeated } \\
\text { addition (or whole number rescaling), } \\
\text { or to Cartesian arrays }\end{array}$ & $\begin{array}{l}\text { Multiplication corresponds to } \\
\text { composition of operators, or to } \\
\text { rectangular area (in which case the } \\
\text { product is a different species of } \\
\text { quantity.) }\end{array}$ \\
\hline $\begin{array}{l}\text { Whole numbers are denoted with base- } \\
10 \text { positional notation }\end{array}$ & $\begin{array}{l}\text { Fractions are denoted with the fraction } \\
\text { bar notation }\end{array}$ \\
\hline $\begin{array}{l}\text { Computational algorithms are anchored } \\
\text { in this notation }\end{array}$ & $\begin{array}{l}\text { Computational algorithms are anchored } \\
\text { in this notation }\end{array}$ \\
\hline $\begin{array}{l}\text { Whole numbers are born in the } \\
\text { cardinal/ordinal world }\end{array}$ & $\begin{array}{l}\text { Fractions are born in the worlds of } \\
\text { (possibly continuous) measure. (The } \\
\text { cardinal world is one of these, though it } \\
\text { is not typically seen this way.) }\end{array}$ \\
\hline
\end{tabular}

\subsubsection{The Continuum Gap}

The passages from rational numbers to irrationals, and then to real numbers is fragmentary and pretty much clouded in mystery in the school curriculum. The student may know little more than, "some numbers are irrational." To build the real numbers with analytic rigor might exceed the resources of many school curricula, with the result that students are left with a weakly developed concept image of real numbers. How would a high school student explain the meaning of $\sqrt{ } 2+\pi$, or $\sqrt{ } 2 \cdot \pi$ ? Or $2^{\pi}$ ("the product of $\pi$ copies of 2?)" Our base-10 algorithms act first on the right most digits, and so could not be applied to infinite decimal expansions.

\subsection{The Occupation Narrative of the Real Number Line}

I contrast the construction narrative with what I call the occupation narrative of the real number line. Its cognitive premise is that, in addition to our early sense of counting, we come also with some primordial sense of continuous, pre-numerical measurement of quantity. This is an idea advanced and developed notably by Davydov (1975), and it is supported by current research:

Children's understanding of measurement has its roots in the preschool years. Preschool children know that continuous attributes such as mass, length, and weight exist, although they cannot quantify or measure them accurately. Even 3-year-olds know that if they have some clay and then are given more clay, they have more than they did before. Preschoolers cannot reliably make judgments about which of two amounts of clay is more; they use 
perceptual cues such as which is longer. At age 4-5 years, however, most children can learn to overcome perceptual cues and make progress in reasoning about and measuring quantities. Measurement is defined as assigning a number to a continuous quantity.

-Clements and Stephan (2001, pp. 2-3)

In this perspective the line is, intuitively, the natural environment for linear measurement, of quantities of length, measured by intervals on the line. Intuitively, the line is like a stretch of string - inelastic, so that length is not distorted-but flexible — so that, for example, it can measure your hat size as well as your height. Eventually it is allowed to have infinite extent in both directions.

It is in this sense that the (continuous) geometric line is made intuitively present from the early grades, and, as new kinds of numbers are introduced, they quickly take up residence on the line. In contrast with the construction narrative, wherein more and more points are installed to build the line, all points are present from the start in the occupation narrative, and more of them acquire numerical names across the curriculum. The numbers are like the "addresses" assigned to the geometric points. One could think of this as "coordinatizing the geometric line," or "Cartesian coordinates in dimension one."

The geometric line is coordinatized with numbers by choice of an ordered pair of points, that we typically call 0 and 1 . Then we take the interval $[0,1]$ as the unit of linear measure. Note that the line has an intrinsic "linear structure," arising from "betweenness:" Given three points, one will lie between the other two. This does not yet specify which one is largest. There are two possible "linear orders" on the geometric line. In choosing the ordered pair $(0,1)$ we specify not only the unit of measure $[0,1]$, but also the order (orientation) of the line, by declaring that 1 is greater than 0 , so 0 to 1 is the positive direction on the line. Our general convention is to depict the line horizontally, and to take (left $\rightarrow$ right) as the positive direction.

A whole number $\mathrm{N}$ is then placed on the line by concatenating, to the right, $\mathrm{N}$ copies of the unit, starting at 0 , and placing $\mathrm{N}$ at the final right endpoint. Note that this placement is essentially measure theoretic, not based exclusively on cardinal. Children are sometimes confused by counting hash marks, where the copies of the unit meet, instead of counting intervals. Fractions are similarly placed on the line using a subunit $[0,1 / \mathrm{d}]$, where $\mathrm{d}$ is the denominator of the fraction.

This in fact foreshadows the general geometric concept of number on the (coordinatized) number line: A point a on the number line represents the number which is the measure of the oriented interval from 0 to a. (This will be negative if 0 lies between a and 1.) In fact, one may reasonably think of the oriented interval $[0, a]$ as a one-dimensional vector. From this point of view, adding a to a general number $\mathrm{x}$ can be geometrically viewed as translation of the line by the vector $[0, a]$ : a given distance in a given direction.

\section{Davydov's Approach}

Young children have a primordial sense of

- quantity, an attribute of physical objects (not only cardinalities): length, area, volume, weight, ... without numerical associations. 
- And of addition (composing and decomposing quantities of the same species)

- They can make rough comparisons of size ("Which is more?"), which Davydov has them express symbolically, as " $\mathrm{B}>\mathrm{T}$." And then infer that " $\mathrm{B}=\mathrm{T}+\mathrm{C}$ " for the "quantity difference" Venenciano and Dougherty (2014) describe this as "Concurrent representation used to model change from a statement of inequality to a statement of equality"

Using two unequal areas of paper, the papers can be stacked such that the area of the
larger piece that is not covered by the smaller piece can be cut off. The piece that is
removed is defined as the difference. Similarly, beginning with the unequal areas of
paper, by taping the precise amount of area to the smaller area to create a combined area
equal to the larger area, defines the difference.
Given quantity B $>$ quantity T: If B $-\mathrm{C}=\mathrm{T}$ then B $=\mathrm{T}+\mathrm{C}$, i.e. "B $=$ T by C."
The last statement is read, "Quantity B is equal to quantity T increased by the
difference, quantity C."

- Davydov develops in children such algebraic relations, involving "pre-numerical" quantities, and hence involving no numerical calculation.

- This practice also functions as a pre-cursor of algebraic thinking.

- And it imparts the correct sense of the meaning of the "=" sign, meaning that the (eventually numerical) value of the two sides is the same. This meaning is sometimes distorted when equations are used primarily in the context of numerical computation: Students come to think that, "the right side is the computation of the left side."

- Davydov develops these ideas in first grade, prior to the introduction of whole numbers, in a measurement context. Whole numbers appear only late in the first term of first grade.

\subsection{Quantity, Unit, Measure, Number}

A quantity has no intrinsically attached number. Rather, given two quantities, A and U, then, taking U as a "unit," the number we attach to A is, "How much (or many) of $U$ is needed to constitute A?" Thus a number is a ratio of two quantities.

To understand a numerical quantity, it is necessary to specify, or know, the unit. And, for a given species of quantity, different units may be chosen: (feet, inches, meters - for length), (quarts, pints, liters - for liquid volume), etc. To numerically simplify a sum of two numerical quantities they must be of the same species and expressed with the same unit. ("Can't add applies and oranges.") That is why, in place value algorithms for addition, we vertically align the digits with the same place value position, i.e. with the same base-10 units. That is why, in adding fractions, we seek common denominators ("unit fractions").

In principle, numerical quantities manifest the full continuum of (positive) real numbers. Whole numbers arise, in every measure regime, when a quantity is composed exactly of a set of copies of the unit. This is how to comprehend whole numbers in the general measure context, not simply cardinal counting. (In the cardinal world, 
the default unit is the one element set, and each set is composed of a set of copies of this unit.)

Of course cardinal can be viewed as a (discrete) measurement context. However, since it is natural to choose the one-element set as unit, there is no a priori need to even introduce the concept of unit. Thus, in the cardinal introduction of whole number, the very concepts of unit, and of measure relative to a unit, do not immediately rise to conscious consideration. Later, when introducing multiplication, and place value, other sets are taken to function as units, but again this typically is not explicitly linked conceptually to the domain of continuous measure. This is related to the "whole number/fraction divide" discussed above.

This notion of number as a ratio of quantities may seem somewhat sophisticated, and not appropriate for very young children. Davydov argues the contrary, as demonstrated by the following activity design, to solve what he calls the "fundamental problem of measure:" Given a quantity A, reproduce $A$ in a different place and time.

Here is how he enacts this with children: See Moxhay (2008).

1. A strip of tape, A, is on a table. In the next room is a roll of tape.

2. Task: Cut off a piece of that roll of tape exactly the length of A. But you are not allowed to move A.

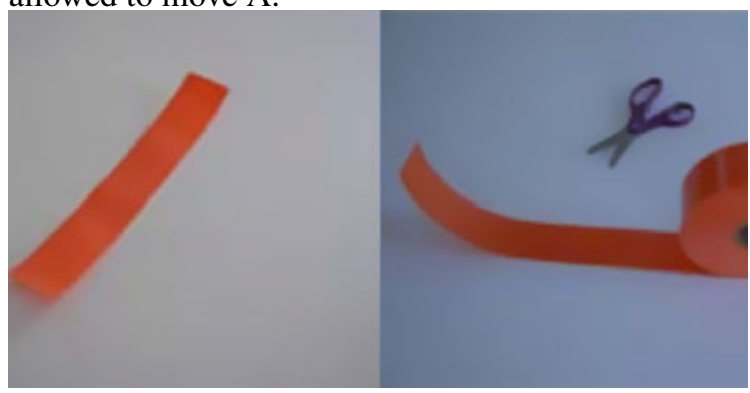

3. Different approaches:

1. Make a guess, from a remembered image. This is very inexact.

2. If given a spool of string and scissors, cut off a piece of string the length of A. This is exact, but needs a customized mediating equivalent quantity, the string segment.

3. Suppose you are given a stick of wood, longer than A. Mark it at the length of $\mathrm{A}$, and use this to measure off the tape.

4. Suppose you have a stick of wood shorter than A. Then you can count off lengths of the stick to measure A. In this case, the child actually constructs the idea of measurement, and engages the concept of unit. 


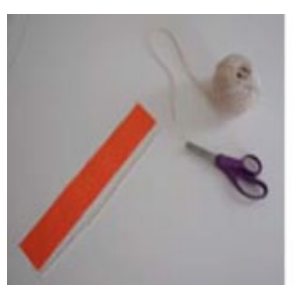

Case 2

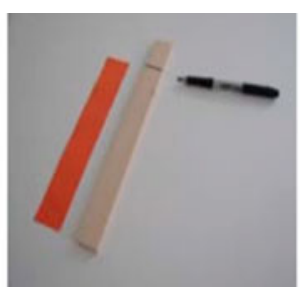

Case 3

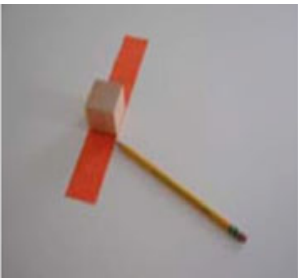

Case 4

5. Of course the short stick of wood will not, in general, measure A exactly. A number of iterates of the stick will measure a part of A with a remainder shorter than the stick. But then, since the stick is longer than that remainder, the remainder can be captured as in step 3 .

This activity design, which leads the learner to the concepts of measure and of unit, creates what Harel (2003) calls intellectual necessity, and exemplifies a didactical situation, in the sense of Brousseau (1997). If we imagine this experiment with cardinal instead of linear measure, several conceptual and cognitive steps would be missing, and the first approach would suffice.

\subsection{Who Was Vasily Davydov?}

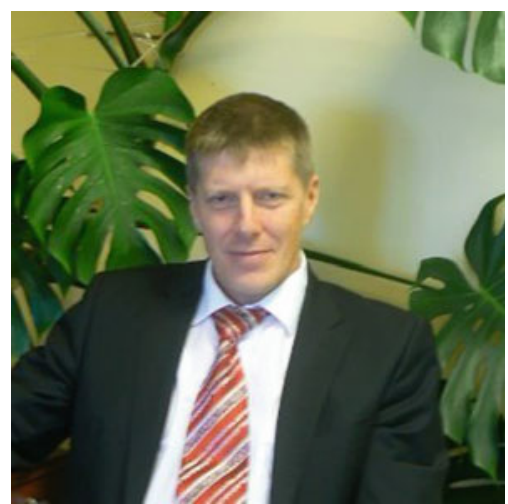

Vasily Davydov (1930-1988) was a Vygotskian psychologist and educator in the Soviet Union. With colleagues, in the 1960s, he developed a curriculum starting with quantity (of real objects) and measure. Adaptations of the Davydov early grades curriculum have been implemented in the U.S., with some claims of success. See, for example: Schmittau (2005), and Moxhay (2008). Many of these ideas are present in the NCTM and Common Core Standards, in the context of measurement, but not integrated with the development of number.

In Bass (1998) I speculated about the possibility of an early introduction of the continuous number line in the school curriculum, without then being aware of Davydov's work. 


\subsection{Conclusion: What Is Achieved by the Occupation Narrative of the Number Line?}

- As mentioned earlier, Davydov's early introduction of pre-numerical quantities provides an introduction to algebraic notation and relations, and to a robust sense of the meaning of the "=" sign.

- The whole number/fraction divide is bridged: The part-whole introduction of fractions is inherently a measurement approach, the whole being the unit of measure. Though cardinal counting is also a measurement context, that point of view is not emphasized, since there is a natural default choice of unit (the 1-element set), and so the very concept of unit, and its possible variability, need not at first enter conscious reflection or discussion. Here it is proposed that one emphasize the appearance of whole numbers in every measurement context. In fact, placement of whole numbers on the number line already requires appeal to (continuous) linear measure.

- The main point is that the geometric line, anchored in the context of linear measure, is present almost from the beginning. The progressive enlargements of the number world simply supplies numerical names to more and more of the (already present) points on the line.

- While a few irrational numbers can be identified and located on the number line, it can be pointed out that many (even "most") numbers are irrational, and that even though we have not named them, they are there, as points on the geometric number line, leaving no "holes" (the line is connected).

- The number line makes it possible, from the beginning, to geometrically interpret the operations of adding, or multiplying by, a real number. (See Ji Yeong and Dougherty (2015) for a measurement treatment of multiplication.)

\section{References}

Bass, H. (1998). Algebra with integrity and reality. Keynote Address at the NRC Symposium on the Nature and Role of Algebra in the K-14 Curriculum. Proceedings published by the NRC.

Brousseau, G. (1997). Foundations and methods of didactique. In N. Balacheff, M. Cooper, R. Sutherland, \& V. Warfield (Eds. and Trans.). Theory of didactical situations in mathematics: Didactique des mathématiques, 1970-1990 (pp. 21-75). Dordrecht, The Netherlands: Kluwer.

Butterworth, B. (2015). Low numeracy: From brain to education. Plenary address at ICMI Study 23, Macau, China, June 2015.

Chislenko, E., \& Tschinkel, Y. (2007). The Felix Klein protocols. Notices of the AMS, 54, 960-970.

Clements, D. H., \& Stephan, M. (2001). Measurement in PreK-2 mathematics. In D. H. Clements, J. Sarama, \& A.-M. DiBiase (Eds.), Engaging young children in mathematics. Reston: NCTM.

Davydov, V. V. (1975). Logical and psychological problems of elementary mathematics as an academic subject. In L. P. Steffe (Ed.), Children's capacity for learning mathematics (pp. 55-107). Chicago, IL: University of Chicago.

Davydov, V. V. (1990). Types of generalization in instruction: Logical and psychological problems in the structuring of school curricula. Reston, VA: National Council of Teachers of Mathematics (Original published in 1972). 
Freudenthal, H. (1983). Didactical phenomenology of mathematical structures. Dordrecht: Reidel. Harel, G. (2003). The DNR system as a conceptual framework for curriculum development and instruction. In R. Lesh, J. Kaput, E. Hamilton, \& J. Zawojewski (Eds.), Foundations for the future. Mahwah: Lawrence Erlbaum Associates.

Howe, R. (2011). The greatest calamity in the history of science. In J. C. e Silva (Ed.), ICMI Newsletter (Vol. 18).

ICMI Study 13. (2006). In F. Leung, K.-D. Fraf, \& F. Lopez-Real (Eds.), Mathematics education in different cultural traditions-A comparative study of East Asia and the West. Berlin: Springer.

Ji Yeong, I., \& Dougherty, B. (2015). Linking multiplication models to conceptual understanding in measurement approach. In 11th Hawaii International Conference of Education, Honolulu, HI. https://www.researchgate.net/publication/270279409_Linking_Multiplication_Models_to_ Conceptual_Understanding_in_Measurement_Approach.

Klein, F. (2000). The Evanston colloquium. AMS Chelsea: Providence.

Moxhay, P. (2008). Assessing the scientific concept of number in primary school children. Paper presented at ISCAR 2008, San Diego. lchc.ucsd.edu/MCA/Mail/xmcamail.2009_05.dir/ pdfxxr6FcSxae.pdf.

National Research Council. (2009). In C. T. Cross, T. A. Woods, \& H. Schweingruber (Eds.), Mathematics learning in early childhood: Paths toward excellence and equity. Committee on Early Childhood Mathematics, Center for Education, Division of Behavioral and Social Sciences and Education. Washington, DC: The National Academies Press.

Schmittau, J. (2005). The development of algebraic thinking: A Vygotskian perspective. ZDB, 37. lchc.ucsd.edu/mca/Mail/xmcamail.2014-11.dir/pdfv7AHOJXcb2.pdf.

Venenciano, L. \& Dougherty, B. (2014). Addressing priorities for elementary school mathematics. For the Learning of Mathematics, 34. http://flm-journal.org/Articles/ 739D3FD8C95A0A3770B35494FA3327.pdf.

Open Access This chapter is licensed under the terms of the Creative Commons Attribution 4.0 International License (http://creativecommons.org/licenses/by/4.0/), which permits use, sharing, adaptation, distribution and reproduction in any medium or format, as long as you give appropriate credit to the original author(s) and the source, provide a link to the Creative Commons license and indicate if changes were made.

The images or other third party material in this chapter are included in the chapter's Creative Commons license, unless indicated otherwise in a credit line to the material. If material is not included in the chapter's Creative Commons license and your intended use is not permitted by statutory regulation or exceeds the permitted use, you will need to obtain permission directly from the copyright holder.

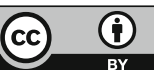

